\title{
THE RELATIONSHIP BETWEEN SOCIAL MEDIA USE FOR ENTREPRENEURSHIP ACTIVITIES AND ENTREPRENEURSHIP MOTIVE: A STUDY ON UNIVERSITY STUDENTS
}

\author{
DOI: 10.17261/Pressacademia.2019.1090 \\ PAP-V.9-2019(37)-p.186-191
}

\section{Ozge Erestin ${ }^{1}$, Serhat Erat ${ }^{2}$}

${ }^{1}$ Gebze Technical University, Faculty of Business Administration, Department of Science of Strategy, 41400, Gebze, Kocaeli, Turkey. ozgerstn@outlook.com, ORCID ID: 0000-0003-0134-9506

${ }^{2}$ Gebze Technical University, Faculty of Business Administration, Department of Science of Strategy, 41400, Gebze, Kocaeli, Turkey. erat@gtu.edu.tr, ORCID ID: 0000-0003-0227-8914

\section{To cite this document}

Erestin, O., Erat, S. (2019). The relationship between social media use for entrepreneurship activities and entrepreneurship motive: a study on university students. PressAcademia Procedia (PAP), V.9, p.186-191

Permemant link to this document: $\mathrm{http} / / /$ doi.org/10.17261/Pressacademia.2019.1090

Copyright: Published by PressAcademia and limited licenced re-use rights only.

\begin{abstract}
Purpose- Nowadays, with the advancement of technology, social media came to our lives and is started to be used with other purposes, as well. Specifically, entrepreneurs perceive social media platforms very appealing for the opportunities that they provide. People with entrepreneur sprit use social media for their entrepreneurship activities in line with their entrepreneurship motives and their entrepreneur characteristics. The purpose of this study is to determine the effects of university students' use of social media for entrepreneurship on entrepreneurship objectives.

Methodology- The sample of the study is composed of 324 university students from different fields in Gebze Technical University. The collected data is analyzed with SPSS statistical software.

Findings- Results of the analysis shows that cognitive and self-sufficiency aspects of social media use for entrepreneurship have positive effects on entrepreneurship objectives.

Conclusion- Conclusion: University students' use of social media for entrepreneurship activities increases their entrepreneurship motives. In addition to the use of social media for social objectives, university students research for what they can do for their career plans, which will shape their future, try to develop their entrepreneur characteristics and use social media for these objectives.
\end{abstract}

Keywords: Social media use for entrepreneurhip objectives, entrepreneurship motive, entrepreneurship JEL Codes: M1,M10, M13

\section{GiRişiMci AMAÇLI SOSYAL MEDYA KULLANIMI VE GiRişiMciliK NiYETi iLişKisi: ÜNIVERSiTE ÖĞRENCILERI ÜZERINE BIR ARAŞTIRMA}

\section{ÖZET}

Amaç- Günümüzde teknolojinin gelişmesiyle birlikte sosyal medya kullanımı hayatımıza girmiş ve farklı amaçlarla kullanılmaya başlanmıştır. Özellikle girişimcilik konusunda sağladığı rahatlıklar çerçevesinde sosyal medya platformları girişimci olmak isteyen bireylere cazip gelmektedir. Girişimcilik ruhuna sahip bireyler, kendilerinde taşıdıkları girişimci kişilik özellikleri ve girişimcilik niyetleri doğrultusunda sosyal medyayı girişimcilik faaliyetlerini hayata geçirmek için kullanmaktadır. Bu araştırmanı amacı, üniversite öğrencilerinin girişimcilik amacıyla sosyal medya kullanımlarının girişimcilik niyetlerine etkisini belirlemektir.

Yöntem- Araştırmanın örneklemi, Gebze Teknik Üniversitesi’nde farklı bölüm ve farklı sınıf seviyelerinde öğrenim gören kolayda örnekleme yoluyla ulaşılmış 324 öğrenciden oluşmaktadır. Elde edilen veriler, SPSS istatistik programı ile analizlere tabii tutulmuştur.

Bulgular- Yapılan analizler neticesinde girişimci amaçlı sosyal medya kullanım boyutları olan bilişsel kullanım boyutu ve öz yeterlilik boyutu ile girişimcilik niyetini anlamlı ve pozitif yönlü olarak etkilediği belirlenmiştir.

Sonuç-. Üniversite öğrencilerinin girişimci amaçlı sosyal medya kullanımları girişimcilik niyetlerini artırmaktadır. Üniversiteli genç bireylerin, sosyal medya da sadece sosyal amaçlı gezinmenin dışında, geleceklerine yön verecek kariyer planlaması ile ilgili neler yapabileceklerini araştırmakta ve özellikle de daha önce yapılan girişim çalışmalarından da etkilenerek, girişimcilik özelliklerini de geliştirmeye çalıştıkları ve bu amaçla sosyal medyayı kullandıkları görülmektedir.

Anahtar Kelimeler: Girişimci amaçlı sosyal medya kullanımı, girişimcilik niyeti, girişimcilik JEL Kodları: M1, M10, M13 


\section{GíRiş}

Teknolojilerin gelişmesi, internetin hayatımıza girmesi ve sosyal medya kavramıyla tanışmamı yaşam biçimimiz ve anlayışımıza yansımaktadır. Günümüzde teknolojinin hızla gelişim göstermesiyle birlikte sosyal medya kullanımı artmakta ve farklı alanlarda kullanımı gözlemlenmektedir. Özellikle sosyal medya kullanımı, günlük yaşamımıza etki etmenin yanında, alışkanlıklarımıza, iletişim kurma yöntemlerimize, girişimcilik faaliyetlerimize, girişimci olma niyetlerimize etki etmektedir. Yeni açılan kanallar sayesinde klasik girişimcilik anlayışları farkıılaşmışır. Teknolojinin gelişmesiyle beraber girişimcilik faaliyetleri de farklı alanlarda ve farklı şekillerde karşımıza çıkmaktadır. Sosyal medya da bu alanların başında gelir. Girişimcilere sağladığı çeşitli avantajlar sayesinde, sosyal medya girişimcilik niyeti taşıyan bireylerin tercih ettiği bir faaliyet alanı olarak karşımıza çıkar. Girişimci olmak isteyen bireyler, kendilerinde bulunan girişimci kişilik özellikleri ve girişimci olma niyetleriyle harekete geçerek sosyal medya alanında girişimcilik faaliyetinde bulunmaktadırlar. Gerek maliyet açısından gerek sağladığı birçok kolaylık açııından günden güne tercih edilen bir faaliyet alanı olmuştur.

$\mathrm{Bu}$ araştırma da girişimci amaçı sosyal medya kullanımı boyutları olan bilişsel kullanım ve öz yeterlilik ile girişimcilik niyeti arasında ki ilişki incelenmiştir. Literatürde sosyal medya kullanımı ile girişimcilik niyeti ilişkisini inceleyen birçok çalışmaya rastlanılmıştır. Ancak yapılan literatür taraması neticesinde ortaya koymuş olduğumuz modele bilgimiz dahilinde ulusal alan yazında rastlanılmazken uluslararası literatürde ise konuya yakın az sayıda araştırmaya rastlanılmışır. Literatürde özellikle; genel amaçlı sosyal medya kullanımı ile ilgili araştırmalar göze çarparken az sayıda girişimcilik amaçlı sosyal medya kullanımı ile ilgili araştırma bulunmuştur. Araştırma bu amacıyla literatüre önemli katkıda bulunacağı düşünülmektedir.

\section{LITERATÜR INCELEMESi}

\subsection{Girişimci Amaçlı Sosyal Medya Kullanımı}

Sosyal medya, insanların birbirleri arasında düşüncelerini, deneyimlerini, yaşam görüşlerini, tarzlarını paylaşmak için kullandıkları, aynı zamanda sürekli iletişim halinde kalmalarını sağlayan sosyal platformlardır (Aktan, 2017). Bu platformlar, bireylere izin veren ve çeşitli olanaklar sunan etkileşimli platformlardır. Web tabanlı ya da mobil tabanlı teknolojilerin kullanılarak oluşturulduğu sosyal medya platformları, kullanıııların içerikler oluşturduğu, paylaşımlarda bulunduğu, iletişim ortamları yarattığı, geliştirdiği ortamlardır (Kietzmann vd., 2010).

Sosyal medya, dünya üzerinde hızla gelişmekte ve ilerlemektedir. İnsanların bilgilerini, deneyimlerini, olaylara bakış açılarını, yorumlarını hızla ve daha yoğun bir biçimde paylaşmaları, sosyal medyanın gelişmesine ve büyümesine neden olmaktadır. Sosyal medya insanlar arasındaki sınırları ve mesafeleri ortadan kaldırarak yeni çevrimiçi ortamlar oluşturmaktadır (Weinberg, 2009). Bireylerin birbiriyle olan iletişimi ve paylaşımı sosyal medyanın özünü meydana getirmektedir. Forumlar, sosyal ağlar, bloglar, wikiler, içerik toplulukları, anlık mesajlaşma uygulamaları, sosyal paylaşım siteleri ve uygulamaları gibi pek çok sosyal platform bireylerin birbiri ile bağlantı kurmasını ve paylaşımlar yapmasını sağlamaktadır (Öztürk \& Talas, 2015).

Sosyal medya kişiler arası iletişim ve paylaşıma katkı sağlamanın yanında birçok alanda insanlara farklı bakış açıları sunmuştur. Bu alanlardan biri de girişimcilik olarak karşımıza çıkmaktadır. Girişimcilik kavramı da son dönemde sosyal medya girişimciliği kavramına dönüşüp yeni bir terim oluşturmuştur. Sosyal medya girişimciliği özellikle girişimciliğin taşıdığı risklerin daha az olduğu bir alan olması sebebiyle kişiler arasında ilgi çekmeye başlamıştır (Çiçek, 2018).

\subsection{Girişimci Amaçı Sosyal Medya Kullanımı Boyutları Bilişsel Kullanım ve Öz Yeterlilik Boyutu}

Sosyal medya kullanımı ölçümlenirken karşımıza çıkan ve çalışmamızda da kullandığımız iki boyut bulunmaktadır. Bu boyutlar bilişsel kullanım ve öz yeterlilik boyutlarıdır. Bu boyutlardan bilişsel kullanım, sosyal medya kullanılarak bireylerin çeşitli içerikler oluşturması, bu içerikleri sosyal medya kullanan diğer bireylerle paylaşması durumunda karşımıza çıkmaktadır. Bilişsel kullanım, üretilen içeriklere diğer kullanıcıların da erişmek için sosyal medya platformlarını kullanması, paylaşılan hikayeleri, resimleri, videoları beğenmesi ve paylaşması olarak da tanımlanır (Hossam vd., 2015). Bilişsel kullanım boyutu, bireylerin bir alanda kendi ortaya koydukları içeriklere ek olarak başkalarının da paylaştıkları içeriklerin belirlenen ortak bir dil, kodlama ile paylaşılmasıyla daha anlaşııı olmasını ifade etmektedir (Hooff ve Huysman, 2009). Öz yeterlilik, insanların hissettiklerini, duygu ve düşüncelerini nasıl yönlendirdiklerini, kendilerini nasıl motive ettiklerini belirleyen bir olgudur (Bandura, 1997). Sosyal medyanın öz yeterlilik boyutu da, sosyal medyayı kullanan bireylerin bir işe başlamak için kullanma kabiliyetine inançları olarak tanımlanır. Sosyal medya öz yeterliliği çeşitli yöntemler kullanılarak arttıılabilir. Sosyal medya eğitimi, sağlanan finansal destekler sayesinde artan sosyal medya öz yeterliliği sosyal medyanın girişimci faaliyetler için kullanılmasına olanak sağlar. Sosyal medya öz yeterliliği, bireylerin bir işe başlamak için sosyal medyayı kullanma beceri seviyesi olarak da karşımıza çıkar (Ajjan vd., 2015).

\subsection{Girişimcilik Niyeti}

Niyet kavramı, Bird tarafından zihnin odak noktası olarak tanımlanmıştır. Kişinin kendi amaçlarına doğru hareket etmesi ve isteklerine ulaşma yoludur. Girişimcilik niyeti ise girişimcileri doğrudan etkileyen, yeni girişimlerin ortaya çıkışını, kuruluş yönünü ve şeklini, amacını belirler. Girişimin hayatta kalması, kalkınması, büyümesi ve değişimini de etkilemektedir (Bird, 1988).

Bireylerin, girişimcilik isteklerini ve davranışlarını ortaya koymak veya yeni iş kurma istekleriyle ilgili olarak bir girişimde bulunma, bir girişime katılma istekleri olarak tanımlayabileceğimiz niyetlerini girişimcilik niyeti olarak tanımlamak mümkündür. Girişimcilerde bulunan bu girişimci niyetler, içten gelen cesaret, bağımsızlık ve hırsın dış dünyaya yansıması olarak karşımıza çıkar (Moses vd. , 2016). Girişimcilik niyeti, bireylerin yeni ve bağımsız girişimler yaratması ya da var olan işletmeler içinde yeni değerler yaratması amacılla ortaya koyacağı eylemler olarak da ifade edilebilir (Fini vd., 2009). Girişimcilik genellikle kasıtlı olarak gerçekleştirilen bir eylem olarak karşımıza çıkar. Girişimci kişiler yeni fikirler hayata geçirmeyi amaçlar, ürünleri ve pazarları inceler, fırsatları değerlendirmeyi amaçlar, yeni girişimler yaratır. Tüm bunları planlayarak kasıtlı bir şekilde gerçekleştirir. Bu girişimcinin niyeti olarak tanımlanabilir. Niyet ise yapılan davranışı etkileyen bir motivasyondur. Kişinin 
motivasyonu ne kadar yüksekse işi de o kadar başarılı olur. Bir işi yapmaya ne kadar niyetli ve istekliyse o kadar başarılı olur. Bunlar birbiriyle doğru orantı göstermektedir. Girişimci, girişim hareketinde bulunduğunda ne kadar motiveyse o kadar güçlü sonuçlar elde eder (Hisrich vd., 2017).

\subsection{Girişimci Amaçlı Sosyal Medya Kullanımı ve Girişimcilik Niyeti îlişkisi}

Sosyal medya bireylerin kişisel ya da kurumsal anlamda paylaşım yapabildikleri ve diğer bireylerle etkileşim içinde olduğu bir ortam olarak karşımıza çıkmaktadır. Sosyal medyadaki bu etkileşim kurumlar tarafından yoğun bir biçimde kullanılıyor olsa da kişisel anlamda da bireylerin içerik üretmesine imkan tanımaktadır. Bireysel kullanıcılar bu etkileşim ve dönüşümleri kullanarak girişimcilik niyetlerini ortaya koyma fırsatı bulabilirler. Girişimcilik ruhu taşıyan tüm bireyler fikirlerini hayata geçirerek yeni girişimde bulunabilirler (Kuşay, 2017). Bu anlamda sosyal medyanın bireylerin içindeki girişimci ruhu ortaya çıkardığını söylemek mümkündür. Paylaşım kolaylığı, insanlara tanıtımın yapılabilmesi için ortam sağlaması, geniş kitlelere kolay yollardan ulaşabilme gibi fırsatları bulunan sosyal medya platformları girişimcilik içinde önemli bir ortam sunmuştur. Sosyal medyayı kullanan tüketiciler, istedikleri ürünlere daha kolay erişebilir hale gelmiş ve bireysel girişimciler ya da şirketler tarafından oluşturulan girişimlerle ilgili iletişim kurmaları kolaylaşmıştır (Jagongo \& Kinyua, 2013).

Calvin ve arkadaşları (2018) Nijerya'nın bir eyaletinde yaptıkları çalışmada sosyal medyanın girişimcilik eğilimini geliştirdiğini gözlemlemiştir. Facebook, Whatsapp ve Instagram gibi sosyal medya platformlarının inovasyon ve yaratıcılığı geliştirdiği sonucuna varılmıştır. Youtube'un ise yenilikçiliğe katkı sağladığı gözlemlenmiştir (Calvin vd., 2018). Kuşay (2017)’ de iş gücü alanı olarak sosyal medyanın kullanımını, girişimci kadınlar üzerinde yapmış olduğu bir çalışmayla ortaya koymuştur. Bu çalışma sonucunda sosyal medya platformlarından Instagram aracılığıyla kadınların girişimci ruhlarını ortaya koydukları sonucuna ulaşılmıştır (Kuşay, 2017).

\section{METEDOLOJI VE HIPOTEZLER}

\subsection{Araştırma Örneklemi, Veri Toplama Yöntemi ve Kullanılan Ölçekler}

18 soruluk anket formu kolayda örnekleme yolu ile Gebze Teknik Üniversitesi'nde öğrenim gören 336 öğrenci üzerinde basılı anket ile yüz yüze uygulanmıştır. 12 adet anket eksik ya da hatalı doldurulması nedeniyle araştırmaya dahil edilmemiş ve nihai olarak 324 adet anket analizlere tabi tutulmuştur.

Yine bu araştırma kapsamında, Girişimci amaçlı sosyal medya kullanımı için; Ajjan vd. (2015) tarafından geliştirilen 3 ifadeden oluşan Bilişsel Kullanım ile Hossam vd., (2015) tarafından geliştirilen 5 ifadeden oluşan Öz yeterlilik Boyutlarından oluşan ölçeklerden yararlanılmıştır. Ali vd., (2009) ve Cansız (2007) çalışmalarından yararlanılarak geliştirilen 10 ifadeli ölçek kullanılmıştır.

\subsection{Araştırmanın Modeli Ve Hipotezler}

Yapılan literatür çalışması neticesinde araştırma konusuna bağlı olarak Şekil 1'de ki model kurulmuş ve bu araştırmada iki adet hipotez test edilmektedir.

Şekil 1: Araştırma Modeli

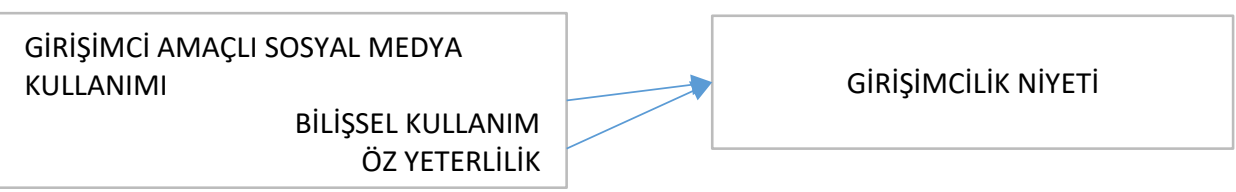

$\mathrm{H}_{1}$ : Girişimci Amaçlı Sosyal Medya Kullanımı Bilişsel Kullanım Boyutu ile Girişimcilik Niyeti Arasında anlamlı bir ilişki vardır. $\mathrm{H}_{2}$ : Girişimci Amaçlı Sosyal Medya Kullanımı Öz Yeterlilik Boyutu ile Girişimcilik Niyeti Arasında anlamlı bir ilişki vardır.

\subsection{Araştırma Bulguları ve Değerlendirme}

Araştırmadaki verilerin analizi SPSS programı kullanılarak sonuçları elde edilmiştir. Bu kapsamda ilk olarak araştırmaya katılan 324 üniversite öğrencisinin sosyo-demografik özelliklerine ilişkin frekans dağılımı yapılmıştır.

Araştırmaya katılanların demografik özelliklerine bakıldığında; ankete katılan öğrencilerin \% $58^{\prime}$ i erkek, \% 42 si ise kadındır. Ankete katılanların \%97'si 21-24 yaş aralığında olup, \%3'ü ise 25-28 yaş aralığındadır. Ankete katılanların sosyal medya kullanımı sıklığına bakıldığında $\% 72$ 'si sürekli, \%15'i nadiren, \%12'si ise az internet kullanma sıklığına sahiptir. Yine İnternette günlük geçirilen süre açısından bakıldığında en fazla \%43 ile 4-6 saat aralığı gözükmektedir. Bunu \%38 ile 1-3 saat, \%15 ile 6 saat ile takip etmektedir. Son olarak İnternette geçirilen sürenin ne kadarı sosyal medyada geçirildiği sorusuna; \%58 i 1-3 saat, \%27 si ise 1 saatten az, \%13 ise 4-6 saat aralığında kullandığını belirtmektedir.

\section{FAKTÖR ANALIZLERI}

Faktör analizi bir ölçeğin yapısal geçerliliğinin test edilmesinde en yaygın kullanılan yöntemlerden biridir. Faktör analizi ile kullanılan ölçeği oluşturan soruların kendi aralarında nasıl kümelendikleri tespit edilir. Faktör Analizine uygunluğunun sınanması için Bartlett Küresellik Testi ve Kaiser-Mayer-Olkin (KMO) ölçütüne bakılmıştır. Tablo 1'de Örneklemin uygunluğu için bulunan KMO değeri 0,889'dur. Bu değişkenler arasında kısmi korelasyonların düşük olup olmadığını göstermektedir. 0,5'den küçük KMO değerleri, değişken çifti arasındaki korelasyonun diğer değişkenlerle açıklanamayacağını ve faktör analizinin uygun olmayabileceğini gösterir. Analizde bulunan değer (KMO = 0,889$)$ kullanılan verilerin faktör analizi için uygun olduğunu gösterir. 
Barlett küresellik testi ana kütledeki değişkenlerin birbiriyle ilişkili olup olmadığı hipotezini test etmektedir. Barlett test sonucunda yaklaşık ki-kare değeri 3620,309 anlamlılık ise 0,000 bulunmuştur. Bu değer korelasyon matrisinin birim matris olduğu şeklindeki sıfır hipotezinin reddedilebildiğini göstermekte ve faktör analizinin kullanılmasının uygunluğunu ortaya çıkarmaktadır.

\section{Tablo 1: KMO ve Barlett's Test Sonuçları}

\begin{tabular}{|l|l|c|}
\hline Kaiser-Meyer-Olkin Measure of Sampling Adequacy. &, 889 \\
\hline \multirow{3}{*}{ Bartlett's Test of Sphericity } & Approx. Chi-Square & 3620,309 \\
\cline { 2 - 3 } & Df & 136 \\
\cline { 2 - 3 } & Sig. &, 000 \\
\hline
\end{tabular}

Tablo 2'de değişkenlere ait keşifsel faktör analizi sonuçları gösterilmiştir. Keşifsel faktör analizi çalışmasında değişkenleri oluşturan 18 soru beklenen şekilde 3 faktöre ayrılmışır. Ortaya çıkan faktörler Girişimci Amaçlı Sosyal Medya Kullanımı Boyutları olan Bilişsel Kullanım Boyutu ve Öz Yeterlilik Boyutu ile Girişimcilik Niyetidir. Açıklanan toplam varyans girdi değişkenleri için \%69,007 dir. Araştırma da kullanılan keşifsel faktör analizi sonucunda anket formundaki değişkenlerinden Girişimcilik Niyetinin bir sorusu beklenen faktörlere yüklenmediği için takip eden analizlerde (Cronbach Alpha güvenilirlik Analizi, Korelâsyon Analizi, Regresyon Analizleri) kullanılmamıştır.

\section{Tablo 2: Faktör Analizi Sonuçları}

\begin{tabular}{|c|c|c|c|}
\hline Kendi işimi kurmama yardımcı olmak için sosyal medya uygulamalarını nasıl kullanacağımı biliyorum. & ,839 & & \\
\hline Girişimci projemi desteklemek için sosyal medya varlığı geliştirmeyi biliyorum. & ,853 & & \\
\hline Yeni firmamı desteklemek için sosyal medya kullanmak benim için kolay olurdu. & ,737 & & \\
\hline Sosyal medyayı; meslektaşlarımla içerik paylaşmak için kullanıyorum. & & ,689 & \\
\hline Sosyal medyayı; meslektaşlarınızla işbirliği içinde olmak için kullanıyorum. & & ,702 & \\
\hline Sosyal medyayı; iş için içerik oluşturmak amacıyla kullanıyorum. & & ,731 & \\
\hline Sosyal medyayı; işimle ilgili bilgileri yaymak için kullanıyorum. & & 835 & \\
\hline Sosyal medyayı; çalışma alanımla ilgili bilgilere ulaşmak için kullanıyorum. & & ,720 & \\
\hline Kendi işimin patronu olma arzusu taşıyorum. & & & 884 \\
\hline Kendi işimi kurmayı çok istiyorum. & & & 892 \\
\hline Benim her zaman girişimciliğe karşı eğilimim var. & & &, 830 \\
\hline Bir gün kendimi girişimci olarak tanımlayabilirim. & & & 814 \\
\hline Başkaları için çalışmaktansa bağımsız ve kendi işimin sahibi olmayı tercih ederim. & & & 806 \\
\hline Eğer bir iş bulamazsam, kendi işimi kurmayı düşünürüm. & & & 641 \\
\hline Başkaları için çalışmak yerine kendi işimde daha fazla para kazanabilirim. & & & ,769 \\
\hline Güvenli ve yüksek ücretli işe sahip olmaktansa kendi işimin sahibi olmayı tercih ederim & & & ,719 \\
\hline Mezun olduktan sonra ciddi olarak kendi işimi kurmayı düşünüyorum. & & & ,770 \\
\hline
\end{tabular}

Tüm değişkenlere ait; ortalamalar, standart sapma değerleri ve (Cronbach Alpha) güvenilirlilik değerleri yukarıdaki Tablo 3'de verilmiştir. Ortalamalara bakıldığında, ankete cevap veren 324 öğrencininin 1'den 5'e Likert ölçeğinin ortanca değeri olan 2,5'un üzerinde değişkenleri olduğu görülmektedir. Alfa güvenilirlilik değerleri ise 0.81 ile 0.92 arasında değişmektedir. (Alfa değerleri 0.70 'in üzerindedir (Nunnally, 1978).

Tablo 3: Korelasyon Analizi

\begin{tabular}{|l|l|c|c|c|c|c|}
\hline & & ort & SS & CrA & 1 & 2 \\
\hline 1 & Bilişsel Kullanım & 4,08 &, 84 & .81 & & \\
\hline 2 & Öz Yeterlilik & 2,97 &, 95 & .85 &, $334^{* *}$ & \\
\hline 3 & Girişimcilik Niyeti & 3,45 &, 94 & .92 &, $368^{* *}$ &, $478^{* *}$ \\
\hline
\end{tabular}

$$
* * p<0,01
$$

Korelasyon katsayı değerleri incelendiğinde tüm değişkenler arasında anlamlı bir ilişki ortaya çıkmıştır. Tüm değişkenler arasında en güçlü korelasyon ilişkisi ise Öz Yeterlilik ile Girişimcilik Niyeti $(r=0.478, p<0.01)$ arasında gerçekleşmiştir. Yine korelasyon tablosunu incelendiğimizde tüm değişkenler arasında pozitif yönlü bir ilişki göze çarpmaktadır.

Bu çalışmada öne sürülen hipotezleri test etmek amacıyla iki adet regresyon modeli oluşturulmuştur. Tablo 4'de Model 1'e ait bağımsız ve bağımlı değişkenlerin anlamlıık düzeyleri ve etkileri gösterilmiştir. 
Tablo 4: Sosyal Medya Bilişsel Kullanım Boyutunun, Girişimcilik Niyetine Etkisi

\begin{tabular}{|c|c|c|c|}
\hline \multirow[t]{2}{*}{ MODEL 1} & \multicolumn{3}{|c|}{ Girişimcilik Niyeti } \\
\hline & Beta & $\mathrm{t}$ & Sig. \\
\hline Bilişsel Kullanım & ,368 & 6,67 &, $000 * *$ \\
\hline $\begin{array}{r}R^{2} \\
F \\
\text { Sig }\end{array}$ & \multicolumn{3}{|c|}{$\begin{array}{c}135 \\
44,578 \\
, 000\end{array}$} \\
\hline
\end{tabular}

$* * p<0,01$

Model 1'de bir hipotez test edilmektedir. Model anlamlıdır (F:44.578, P:0.000). Bağımsız değişkenlerin modeldeki bağımlı değişkenin varyansını açıklama oranı olan $\mathrm{R}^{2}$ değeri 0.135 olarak bulunmuştur. Modeldeki bağımsız değişken Sosyal Medya Kullanımı boyutu olan Bilişsel Kullanım ( $\beta$ : 0.368, p<0.01) değişkeni, Girişimcilik Niyetini artırmaktadır. Bu sonuçlara göre $\mathrm{H}_{1}$ hipotezi desteklenmiştir. Tablo 5'de Model 2'e ait bağımsız ve bağımlı değişkenlerin anlamlılık düzeyleri ve etkileri gösterilmiştir.

Tablo 5: Sosyal Medya Öz Yeterliik Kullanım Boyutunun, Girişimcilik Niyetine Etkisi

\begin{tabular}{|c|c|c|c|}
\hline \multirow[t]{2}{*}{ MODEL 2} & \multicolumn{3}{|c|}{ Girişimcilik Niyeti } \\
\hline & Beta & $\mathrm{t}$ & Sig. \\
\hline Öz Yeterlilik Kullanımı & 478 & 9,175 &, $000 * *$ \\
\hline $\begin{array}{r}\mathrm{R}^{2} \\
\mathrm{~F} \\
\text { Sig }\end{array}$ & \multicolumn{3}{|c|}{$\begin{array}{c}, 228 \\
84,181 \\
, 000\end{array}$} \\
\hline
\end{tabular}

$* * p<0,01$

Model 2'de bir hipotezi test edilmektedir. Model anlamlıdır (F:84.181, P:0.000). Bağımsız değişkenlerin modeldeki bağımlı değişkenin varyansını açıklama oranı olan $\mathrm{R}^{2}$ değeri 0.228 olarak bulunmuştur. Modeldeki bağımsız değişken Öz Yeterlilik Kullanımı ( $\beta$ : $\left.0.478 p<0.01\right)$ değişkeni, Girişimcilik Niyetini artırmaktadır. Bu sonuçlara göre $\mathrm{H}_{2}$ hipotezi desteklenmiştir.

\section{SONUÇ VE ÖNERILER}

Bu çalışmada, öğrenim hayatına devam eden üniversite öğrencilerinin sosyal medya kullanımları, kişilik özellikleri ve girişimcilik niyeti ilişkisi üzerinde durulmuştur. Araştırmanın amacı, bireylerin sosyal medya kullanımlarını ne ölçüde girişimci amaçla yaptıklarını ortaya koyarak, girişimci kişilik özellikleri ve girişimcilik niyeti ilişkisini ortaya koymaktır. Öğrencilerin sosyal medya kullanımlarını hangi ölçüde girişimcilik amacıyla yaptıklarını, girişimci kişilik özelliklerini taşıyıp taşımadıkları ve girişimcilik niyetleri ölçülmeye çalışılmıştır. Yine tüm bu değişkenlerin birbirleri üzerinde yaptıkları etkiler incelenmiştir.

Günümüzde teknolojinin gelişmesiyle birlikte sosyal medya kullanımı hayatımıza girmiş ve farklı amaçlarla kullanılmaya başlanmıştır. Özellikle girişimcilik konusunda sağladığı rahatlıklar çerçevesinde sosyal medya platformları girişimci olmak isteyen bireylere cazip gelmektedir. Girişimcilik ruhuna sahip bireyler, kendilerinde taşıdıkları girişimci kişilik özellikleri ve girişimcilik niyetleri doğrultusunda sosyal medyayı girişimcilik faaliyetlerini hayata geçirmek için kullanmaktadır.

Yapılan analizler neticesinde girişimci amaçlı sosyal medya kullanım boyutları olan bilişsel kullanım boyutu ve öz yeterlilik boyutu ile girişimcilik niyetini anlamlı ve pozitif yönlü olarak etkilediği belirlenmiştir. Bulunan sonuç literatürde genel olarak sosyal medya kullanımı ve girişimcilik niyetini inceleyen benzer çalışmalarla uyumludur (Calvin vd., 2018; Mukolwe ve Korir, 2016; Jagongo ve Kinyua, 2013; Kuşay, 2017). Elde edilen bu sonuca göre üniversite öğrencilerinin girişimci amaçlı sosyal medya kullanımları girişimcilik niyetlerini artırmaktadır. Üniversiteli genç bireylerin, sosyal medya da sadece sosyal amaçlı gezinmenin dışında, geleceklerine yön verecek kariyer planlaması ile ilgili neler yapabileceklerini araştırmakta ve özellikle de daha önce yapılan girişim çalışmalarından da etkilenerek, girişimcilik özelliklerini de geliştirmeye çalıştıkları ve bu amaçla sosyal medyayı kullandıkları görülmektedir.

Bu araştırmanın bazı sınırlılıkları bulunmaktadır. Araştırma sadece devlet üniversitelerinde eğitim gören lisans öğrencileri üzerinde uygulanmıştır. Gelecek çalışmalarda farklı devlet ve özel üniversitelerde ve ayrıca farklı bölümlerde eğitim görenlerde araştırma yapılması bu konuda önemli sonuçlar sağlayacaktır. Diğer bir sınırlılık ise, sadece sosyal medya kullanımı ile girişimcilik niyeti değişkenleri araştırmaya konu olmuştur. Bu yüzden yapılacak gelecek çalışmalarda farklı değişkenlerin araştırmaya dahil edilmesi literatüre daha fazla katkı sağlayacaktır Bununla birlikte çalışanların demografik yapılarının da araştırmalara dahil edilmesi diğer benzer araştırmalarla kıyas yapılmasına imkan sağlayacağı düşünülmektedir. 


\section{KAYNAKÇA}

Ajjan, H., Fabıan, F., Tomczyk, D., (2015). Social Media Use To Support Entrepreneurship ın The Face of Disruptıon. Journal of Developmental Entrepreneurship, 20(3), p.1-27.

Ali, A., Topping, K. J., Tariq, R. H. (2009)..Entrepreneurial Incli-nations of Prospective Teachers,.New Horizons in Education, 56(2), p.1-16.

Aktan, E., (2017). Sosyal Medya ve Siyasal Katılım, Eğitim Yayıncılık, Konya.

Bandura, A. (1994). Self-efficacy. In V. S. Ramachaudran (Ed.), Encyclopedia of human behavior ,Vol. 4, p. 71-81.

Bird, B., (1988).Implementing Entrepreneurial İdeas: The Case For Intention”, Academy Of Managament Review, 13(3), p.442-454.

Calvin O.Y., Isaac O.M., İbrahim A.A., (2018).Impact Of Socıal Medıa On Entrepreneurshıp Development Among Users In Zamfara State. Journal of Economics \& Finance, 2(2), p.303.

Cansız, E. (2007). Üniversite Öğrencilerinin Girişimcilik Özelliklerinin Belirlenmesi: Süleyman Demirel Üniversitesi Öğrencileri Üzerine Bir Çalışma, SDÜ Sosyal Bilimler Enstitüsü İşletme Anabilim Dalı, Yayımlanmamış Yüksek Lisans Tezi, Isparta.

Çiçek, B., (2018).Social Media Entrepreneurship. İçtiamiyat Sosyal Bilimler Dergisi, 2(1), s. 10-17.

Fini R., Grimaldi R., Marzocchi G. L., Sobrero, M., (2009), The Foundation Of Entrepreneurial Intention”, presented at summer Conference, Copenhagen Business School, Denmark, June, 17-19.

Hossam, H. A., Nevo, D., Wade, M.(2015).Linking Dimensions of Social Media Use to Job Performance: The Role of Social Capital. Journal of Strategic Information Systems, 24, p.65-89.

Hisrich, R. D., Peters M. P., Shepherd, D. A.(2017), “Entrepreneurship”, 10th Edication, McGraw Hill Education, New York.

Hooff, B., Huysman, M.(2009).Managing knowledge sharing: Emergent and engineering approaches.Information \& Managament, 46(1), p.18.

Jagongo, A., Kinyua, C.(2013).The Social Media and Entrepreneurship Growth. International Journal of Humanities and Social Science, 3(10), p.213-227.

Kietzmann, J. H., Silvestre, B. S., McCarthy, I. P., Pitt L. F., (2012).Unpacking the Social Media Phenomeon: Towards a Research Agenda. Journal of Publıc Affaırs an International Journal, 12(2), p.109-119.

Kuşay, Y.(2017).İ̧̧ Gücü Alanı Olarak Sosyal Medyanın Kullanımı ve Girişimci Kadınlar.Marmara Üniversitesi Kadın ve Toplumsal Cinsiyet Araştırmaları Dergisi, s.23-33.

Moses, C. L., Olokundun, M. A., Akinbode, M.(2016). Entrepreneurship Education and Entrepreneurial Intentions: The Moderating Role of Passion. The Social Sciences, 11(5), p.645-653.

Mukolwe, E., Korir, J., (2016). Social Media and Entrepreneurship: Tools, Benefits, and Challenges. A Case Study of Women Online Entrepreneurs on Kilimani Mums Marketplace of Facebook. International Journal of Humanities and Social Science, 6(8), p.248-256.

Nunnally, J.C., (1978). Psychometric theory. 2nd Edition, McGraw-Hill, New York.

Öztürk, M.F., Talas M., (2015). Sosyal Medya ve Eğitim Etkileşimi. Journal Of World Of Turks,7(1), s.101-120.

Weinberg, T.(2009). The New Community Rules: Merketing On The Social Web. United States of America. O’Reilly Media. 